\title{
Recurrencia de distrofia granular en injerto corneal
}

\section{Recurrence of granular dystrophy in a corneal graft}

\author{
Bruno de Miranda-Cordeiro ${ }^{1,2 *}$, Paulo H. de Miranda-Cordeiro ${ }^{3}$, y Frederico de Miranda-Cordeiro ${ }^{1,2}$ \\ ${ }^{1}$ Instituto de Olhos Ciências Médicas, Belo Horizonte, Minas Gerais; ${ }^{2}$ AME Excelência em Visão, Congonhas, Minas Gerais; ${ }^{3}$ Universidade Federal \\ de Ouro Preto, Ouro Preto, Minas Gerais. Brasil
}

Mujer de 22 años que refiere deslumbramiento y disminución de la agudeza visual sin mejoría con anteojos o lentes de contacto. Se le diagnosticó distrofia granular corneal y se sometió a queratoplastia penetrante (QPP) en ambos ojos. El procedimiento se realizó sin complicaciones. Después de 12 años de seguimiento (cuando tenía 34 años) regresó refiriendo los mismos síntomas: deslumbramiento y baja agudeza visual en ambos ojos. El examen con lámpara de hendidura mostró los injertos de córnea con opacidades granulares parduscas que afectaban al estroma anterior en la córnea central (Fig. 1). Este caso ilustra la recurrencia de la distrofia granular en injertos de córnea.

El tiempo reportado de recurrencia en la literatura es variable, lo que sugiere que pueden estar involucrados factores genéticos. Algunos estudios informan la recurrencia después de QPP a los 3 a 7 años, mientras que otros la informan después de 10015 años. ${ }^{1,2}$

\section{Conflicto de intereses}

Los autores no tienen conflictos de interés relacionados con este trabajo.

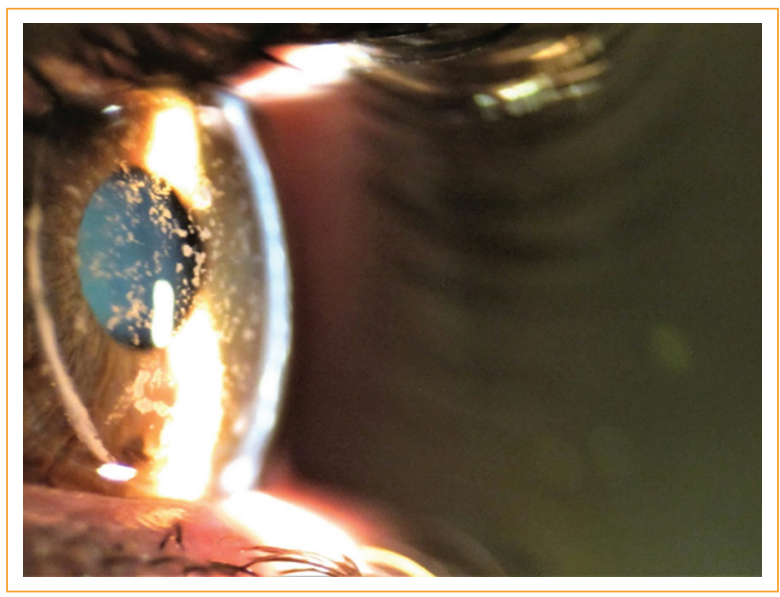

Figura 1. Injerto de córnea con opacidades estromales rodeadas de córnea clara y sana, lo que indica la recurrencia de la distrofia granular corneal. Nótese una línea densa, blanca y circular que representa el límite entre el injerto de córnea y la córnea receptora.

\section{Responsabilidades éticas}

Protección de personas y animales. Los autores declaran que los procedimientos seguidos se conformaron a las normas éticas del comité de experimentación 
humana responsable y de acuerdo con la Asociación Médica Mundial y la Declaración de Helsinki.

Confidencialidad de los datos. Los autores declaran que han seguido los protocolos de su centro de trabajo sobre la publicación de datos de pacientes.
Derecho a la privacidad y consentimiento informado. Los autores han obtenido el consentimiento informado de los pacientes y/o sujetos referidos en el artículo. Este documento obra en poder del autor de correspondencia. 